Article

\title{
Regional Landslide Potential Mapping in Earthquake-Prone Areas of Kepahiang Regency, Bengkulu Province, Indonesia
}

\author{
Arif Ismul Hadi ${ }^{1,2, *(1)}$, Kirbani Sri Brotopuspito ${ }^{3, *}$, Subagyo Pramumijoyo 4 \\ and Hary Christady Hardiyatmo ${ }^{5}$ \\ 1 Physics Department, Universitas Gadjah Mada, 55281 Yogyakarta, Indonesia \\ 2 Department of Physics, Faculty of Mathematics and Natural Sciences, University of Bengkulu, \\ 38371 Bengkulu, Indonesia \\ 3 Department of Physics, Faculty of Mathematics and Natural Sciences, Universitas Gadjah Mada, \\ 55281 Yogyakarta, Indonesia \\ 4 Department of Geological Engineering, Faculty of Engineering, Universitas Gadjah Mada, \\ 55281 Yogyakarta, Indonesia; bagyo@ugm.ac.id \\ 5 Department of Civil Engineering, Faculty of Engineering, Universitas Gadjah Mada, \\ 55281 Yogyakarta, Indonesia; hary@tsipil.ugm.ac.id \\ * Correspondence: ismulhadi@unib.ac.id (A.I.H.); kirbani@ugm.ac.id (K.S.B.)
}

Received: 8 February 2018; Accepted: 17 April 2018; Published: 15 June 2018

\begin{abstract}
Kepahiang regency is an area above the Musi segment of the Sumatran fault system. This condition makes the study area prone to natural disasters such as landslides in the slope area caused by earthquakes due to tectonic plate movement. The objective of this study was to locate potential landslide areas in earthquake-prone areas of Kepahiang regency, Bengkulu province, Indonesia. We performed horizontal to vertical spectral ratio (HVSR) analysis and simple additive weighting (SAW) methods to accomplish the goal. The acquisition of field data involved a broad band seismometer PASI Gemini-2 (triaxial geophone). The microtremor data recorded in the field were then analyzed by the wave spectrum. The results showed that the landslide potential in the study area could be divided into three categories, i.e., low, medium, and high potential. Areas with high potential should be more aware of the threat of landslides, especially in population-dense areas. The greatest threat in the study area is an earthquake along Sumatra's active fault. An earthquake that occurs in a very steep, landslide-prone area can increase risk and trigger a landslide.
\end{abstract}

Keywords: landslide potential; HVSR method; SAW method; Sumatra's active fault

\section{Introduction}

Kepahiang is one of the regencies in the province of Bengkulu, Indonesia that has high rainfall throughout the year. This happens because the area is one of the cross section areas between the wind blowing from Asia and the wind from Australia [1]. Kepahiang Regency is also traversed by the Musi segment of the Sumatra fault system [2]. The area traversed by the fault can trigger ground motion in case of an earthquake. Earthquakes occur along the fault at a rate of $6.1 \times 10^{-3}$ times per year with a minimum magnitude of about M 5.0., representing the highest earthquake occurrence rate of any segment of the Sumatran fault in the Bengkulu region [3].

Hence Kepahiang regency is prone to earthquakes due to tectonic movements along faults and bad weather, which can cause storms, landslides, flooding, etc. High rainfall and earthquakes are both factors triggering landslides. To reduce the risk of landslides in earthquake-prone areas and support disaster mitigation in Kepahiang regency, it is necessary to perform appropriate potential 
landslide mapping of the area. The objective of this study is to map the landslide potential in earthquake-prone areas of Kepahiang regency, Bengkulu Province, Indonesia. To achieve that goal, we used the Horizontal to Vertical Spectral Ratio (HVSR) method and weighted statistic with Simple Additive Weighting (SAW).

The novelty of this study is using a shear strain parameter approach as a land deformation parameter for a landslide potential study correlated with geological internal parameters (e.g., slopes and geological structures) and external (i.e., earthquakes and rainfall) parameters. The parameters are rainfall, slope, distance from faults to measurement point, peak ground acceleration (PGA), and Vs30. Research related to landslides with different approach has been conducted by some previous researchers, like Zhang et al. [4] and Karnawati [5].

In particular, Zhang et al. [4] carried out a research on the characterization of earthquakes and rainfall that could trigger landslides near the epicenter of the Wenchuan earthquake (China) using satellite image interpretation and field verification techniques. The results showed that Wenchuan earthquake on 12 May 2008 with $\mathrm{M}=7.9$ and a depth of $19 \mathrm{~km}$ resulted in 322 shallow landslides. In addition, a total of 351 new landslides caused by high rainfall occurred in Wenchuan area on 14 August 2010.

Karnawati [5] conducted research on the mechanism of rock mass movement due to earthquakes using a geological approach. The research was conducted in an area affected by the 27 May earthquake in Yogyakarta. The geological investigations included an interpretation of aerial photography and a review of regional geological data, field investigations, and engineering geological analysis. The results showed that the earthquake shacking favored the mechanism of wedge-shaped rock mass detachments and slides, the main controlling factors being the orientation of rock layers, and the weathering conditions on slopes steeper than $40^{\circ}$. In addition Hasi et al. [6], demonstrated that the landslide distribution caused by the Iwate-Miyagi earthquake is mainly controlled by coseismic fault ruptures.

Previous research related to landslides in our research area was conducted by Djadja et al. [7] and Sukisno and Muin [8]. Djadja et al. [7] mapped susceptibility in Kepahiang and the surrounding areas. Their research used indirect and direct methods through a geological approach. The indirect method used overlaying analysis to find the effect of factors found on parameter maps on the distribution of ground motion and used Geographic Information System (GIS) analysis. The direct method involved directly mapping the landslide susceptibility zone in the field by taking into account the factors of morphology, geology, land use, and geological structure. The results mentioned that Kepahiang and the surrounding area are divided into four land susceptibility zones, i.e., very low, low, medium, and high susceptibility zones. On the other hand, Sukisno and Muin [8] conducted landslide potentials mapping based on land use directives. They performed a potential analysis of landslide-prone areas using GIS. The result of the research shows that Kepahiang is a potential landslide disaster area with high- and medium-risk zones.

Hadi et al. [9] conducted an initial investigation of potential landslide areas on the cross road of Bengkulu to Kepahiang KM 31 to 60 using microtremor data and the steepness of the topographic slope. The results indicated that the area with the greatest potential for landslides is the inter-city road of Bengkulu to Kepahiang at the 54th kilometer-around Tebatmonok village, Kepahiang subdistrict, Kepahiang regency, with a value of ground shear strain (GSS) of $1.15 \times 10^{-2}$ and a steepness of the slope of $15-30 \%$.

The presence of faults in the study area, as shown in Figure 1, is sufficient to influence its seismic activity. In particular Kepahiang is the main termination area of a dextral fault system with a general northwest-southeast strike and showing active tectonic conditions [10]. There are two main NW-SE segments of the most active Sumatran fault system in the area of Kepahiang, namely the Daspetah fault and the Musi-Keruh fault. Secondary faults are generally in the southwest-northwest direction [11,12]. The distance of data points to the location of faults is from $6.03 \times 10^{-3}$ to $7.125 \mathrm{~km}$. The closer the fault, the higher the risks to the threat of earthquake and landslide will be. 


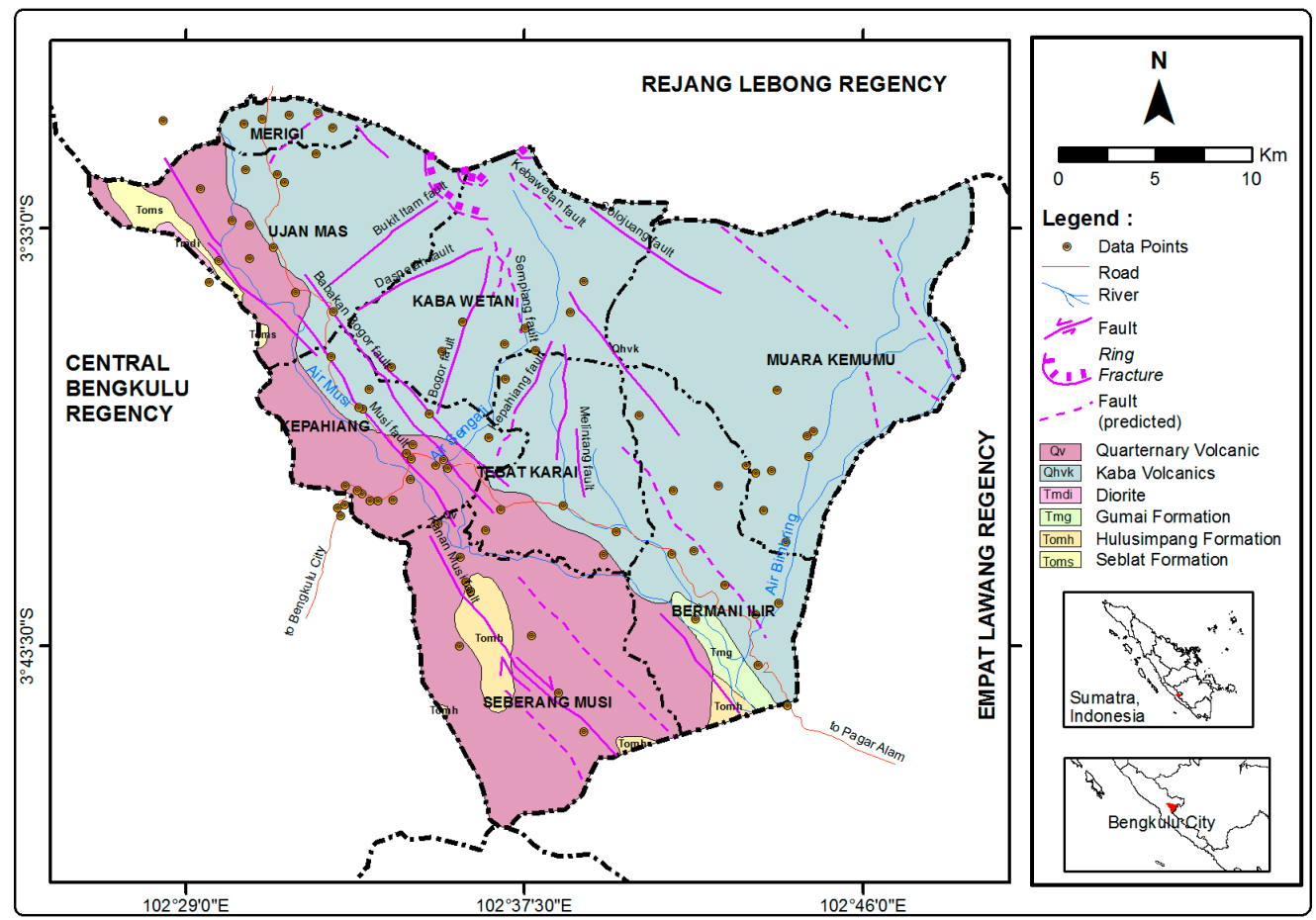

Figure 1. Regional geological map and the existence of a fault of Kepahiang regency, Bengkulu province, Indonesia (modified from Gafoer et al. [11] and Irwanto et al. [12]).

\section{Materials and Methods}

The study area is $\pm 60 \mathrm{~km}$ to the northeast of Bengkulu City. This site can be reached by vehicle in approximately two hours (Figure 2). The steps of the research are data acquisition, data processing and analysis, and interpretation of the obtained data.

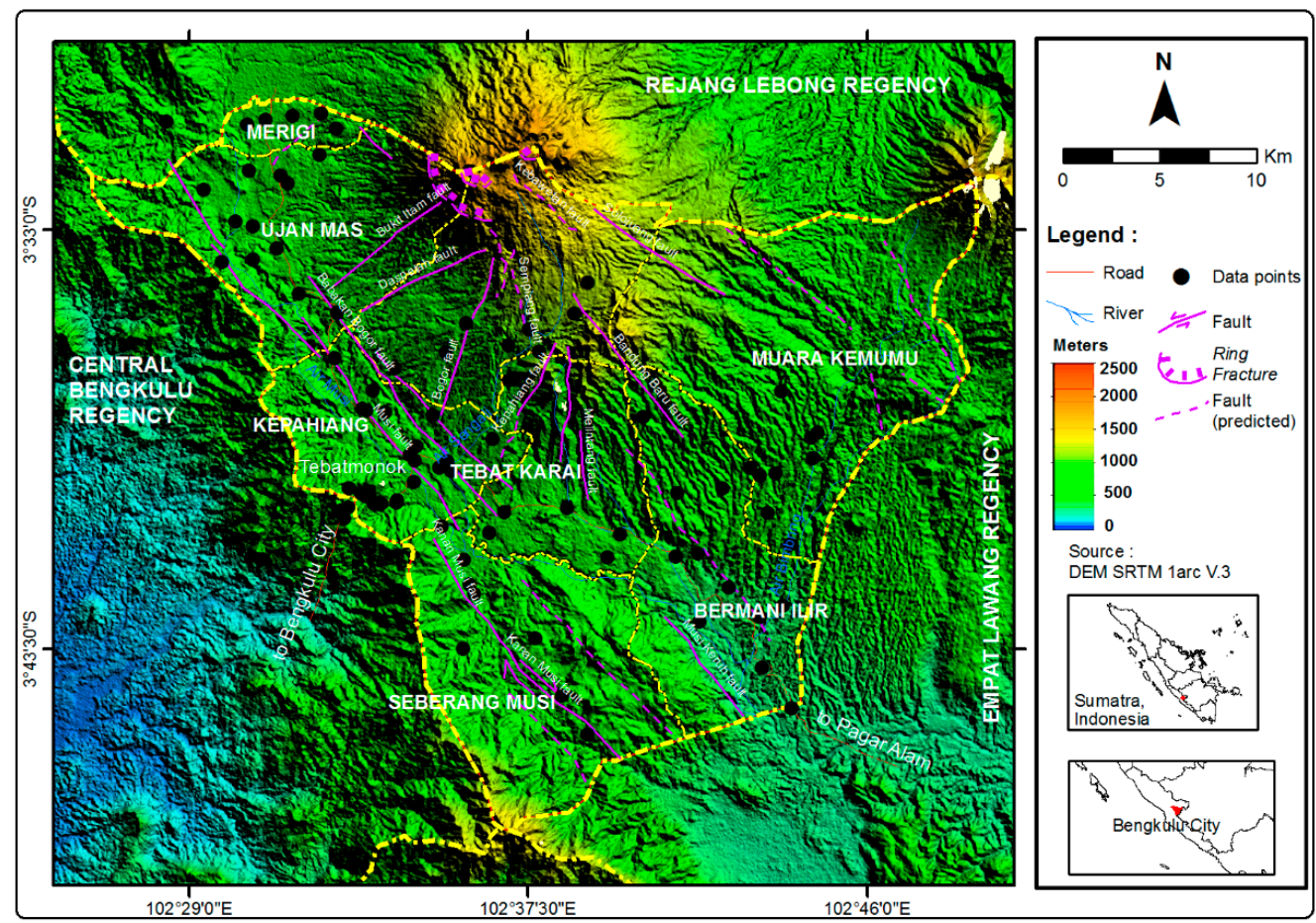

Figure 2. Landslide-prone study area of in Kepahiang regency, Bengkulu province, Indonesia. 


\subsection{Data Acquisition}

The earthquake data were taken from the International Seismological Centre (ISC), the United States Geological Service (USGS), and the Indonesian Agency for Meteorology, Climatology and Geophysics (BMKG) for the last 100-year period in Bengkulu province (1914-2014), with provisions of $\mathrm{Mw} \geq 5$ and a shallow depth $\leq 70 \mathrm{~km}$, which are used as inputs to obtain peak ground acceleration (PGA) values at several points of observation. The location of observation points refers to a DEM-SRTM image map and field condition indicating landslide potential and some previous research results in Kepahiang regency.

The subsurface structures were obtained by using GSS parameters. To determine the GSS value in the field, we used the HVSR method. Data obtained in the field are microtremor data. HVSR is one of the measurement methods to understand the nature of the subsurface structure without damaging the structure. From each observation point, the position and altitude data were taken using a global positioning system (GPS) and the predominant period data of the soil and amplification value by using the broad band seismometer PASI Gemini-2 (triaxial geophone). Microtremor data acquisition refers to the Site Effects Assessment using Ambient Excitation (SESAME) standard. According to SESAME [13], the length of data retrieval will give good results if the predominant frequency at the study site is low enough.

\subsection{Data Processing}

Historical earthquake data in the form of latitude and longitude of the epicenter, magnitude, and seismic depth of the seismic recording are processed to obtain PGA values. The next step is to calculate the distance between the epicenter $(\Delta)$ and the hypocenter $(R)$. The distance of the epicenter and the distance of the hypocenter can be obtained by the following equations [14]:

$$
\Delta=\sqrt{\left(x_{1}-x_{2}\right)^{2}+\left(y_{1}-y_{2}\right)^{2}} \text { and } R=\sqrt{\Delta^{2}+h^{2}},
$$

where $x_{1}$ is the latitude of epicenter, $x_{2}$ is the latitude of observation, $y_{1}$ is the longitude of epicenter, $y_{2}$ is the longitude of observation, and $h$ is the depth of the earthquake source $(\mathrm{km})$. The Probabilistic Seismic Hazard Analysis (PSHA) formula approach is used to obtain PGA bedrock. The calculation of PGA bedrock is obtained using the total probability theory approach. In the general form, the total probability theorem is formulated as follows [15]:

$$
P\left[Y>y^{*}\right]=\iint P\left[Y>y^{*} \mid m, r\right] f_{M}(m) f_{R}(r) d m d r,
$$

where $P\left[Y>y^{*} \mid m, r\right]$ is the probability of an earthquake with $m$ magnitude at a $r$ distance that provides $Y$ maximum acceleration at a location higher than $y, f_{M}(m)$ is the probability of magnitude density function, and $f_{R}(r)$ is the function of distance density.

The microtremor data obtained in the field are still in the time zone consisting of three components, the east-west (EW) component, the north-south (NS) component, and the vertical or up-down (UD) component. The measurement data cannot be processed directly but must be converted into Sesame ASCII Format (SAF). The output of this HVSR method is the amplification value and the predominant frequency of the soil used as the input parameter to produce the value of ground shear strain, GSS $\left(\gamma_{g}\right)$, which is formulated as follows [16,17]:

$$
\gamma_{g}=\frac{A_{g}^{2}}{f_{g}} \times \frac{\alpha}{\pi^{2} v_{b}}
$$

where $A_{g}$ is the amplification factor, $f_{g}$ is the predominant frequency of the ground (Hz), $\alpha$ is PGA in bedrock (gal), and $v_{b}$ is a shear wave velocity in bedrock whose value is $600 \mathrm{~m} / \mathrm{s}$. The microtremor data recorded in the field are then analyzed by the wave spectrum by Win-MASW 5.2 HVSR software 
(PASI, Torino, Italy) so as to obtain the amplification value and the predominant frequency of ground at each point of study site. This value of GSS is used as a parameter to determine the landslide potential limits and the characteristics of the ground subsurface dynamics. Location points that have landslide potential limits and characteristics of ground subsurface dynamics based on the GSS values are then mapped. Since landslide potential is also influenced by geological parameters like slope, geological structure, etc. and external parameters such as rainfall, earthquakes, etc., these parameters are correlated with GSS value at the observation site.

\subsection{Data Analysis and Interpretation}

In the HVSR method, the interpretation and analysis of data based on GSS contour maps are correlated with geological parameters and external parameters at the observation site. After obtaining the parameters from result of analysis by using HVSR method $\left(A_{g}, f_{g}, \gamma\right)$ and PGA as well as geological parameters and external parameters; furthermore, they are correlated thoroughly using SAW statistical methods. The landslide susceptibility assessment must consider the parameters of critical instability according to the assessed object by giving each expected weight value, which is proportional to the relative contribution to the slope failure or landslide [18]. According to Soeters and Westen [19], the operations that should be carried out to find the susceptibility of landslide classes are as follows: subdivide each parameter into a number of relevant classes, assign an obtained weighted value to each class, assign a weighted value obtained to each of the parameter map, overlay the yields of weighted maps, obtain scores of each terrain unit, and then classify all of obtained scores in susceptibility classes. Susceptibility scores obtained with the techniques mentioned above are usually reclassified to obtain susceptibility classes, i.e., high susceptibility, medium, and low [18].

The SAW method is a weighted sum method. SAW method is also part of multi-attribute decision-making (MADM), which is a method to establish the best alternative based on certain criteria. MADM problems evaluate $m$ alternative $A_{i}(i=1,2, \ldots, m)$ against a set of attributes or $C_{j}$ criteria $(j=1$, $2, \ldots, n)$, where each criterion is independent of each other. The decision matrix of each alternative to each criterion $(X)$ is given by [20]:

$$
X=\left[\begin{array}{cccc}
x_{11} & x_{12} & \ldots & x_{1 n} \\
x_{21} & x_{22} & \ldots & x_{2 n} \\
\ldots & \ldots & \ldots & \ldots \\
x_{m 1} & x_{m 2} & \ldots & x_{m n}
\end{array}\right]
$$

where $x_{i j}$ is the $i$-th alternative performance rating against the $j$-th criteria. The weight value indicating the relative importance of each criterion is given by [20]:

$$
W=\left\{w_{1}, w_{2}, \ldots, w_{n}\right\}
$$

The performance rating $(X)$ and weighted value $(W)$ are the primary values that represent the absolute preference of the decision maker. The MADM issue ends with the ranking process to get the best alternative.

The basic concept of the SAW method is to find the weighted sum of performance ratings on each alternative of all criteria [18]. The SAW method requires the process of normalizing the decision matrix $(X)$ to a comparable scale to all existing alternative ratings, which is [20]:

$$
r_{i j}\left\{\begin{array}{l}
\frac{x_{i j}}{\operatorname{Max} x_{i j}}, \text { if } j \text { is benefit attribute } \\
\frac{i}{\operatorname{Min} x_{i j}} \\
\frac{i}{x_{i j}}, \text { if } j \text { is cost attribute }
\end{array},\right.
$$


where $r_{i j}$ is a normalized performance rating of the alternative $A_{i}$ on the attribute $C_{j} ; i=1,2, \ldots, m$ and $j=1,2, \ldots, n$. The preference value for each alternative $\left(V_{i}\right)$ is provided by [20]:

$$
V_{i}=\sum_{j}^{n} w_{j} r_{i j}
$$

and the largest value of $V_{i}$ is the best value selected.

\section{Results}

\subsection{Microtremor Recording}

Microtremor data were obtained in the field at 84 data points by considering the accessibility of the measurement site. Several sites were not suitable for collection because there was no road access, such as in a protected forest. The existing data also sufficiently represent each subdistrict in Kepahiang regency. To obtain good results, field data acquisition was conducted for $30 \mathrm{~min}$ at all study sites [13]. The data were then processed to obtain the natural frequency value of the soil and its amplification factor. An example of a microtremor data recording signal obtained in the field is shown in Figure 3. In Figure 3 it is shown that the microtremor source is derived from the horizontal component (north-south, NS and east-west, EW) and vertical component (up-down, UD). The recorded signal shows a clear difference between the natural vibrations and the transient vibrations. The amplitude of the transient vibrations recorded on the appliance is greater than the natural vibrations of the soil. The transient vibrations are however caused by crowd people activity, traffic activity, vibration of factory machinery, and so on; hence they were considered as noise and not involved in the data processing.

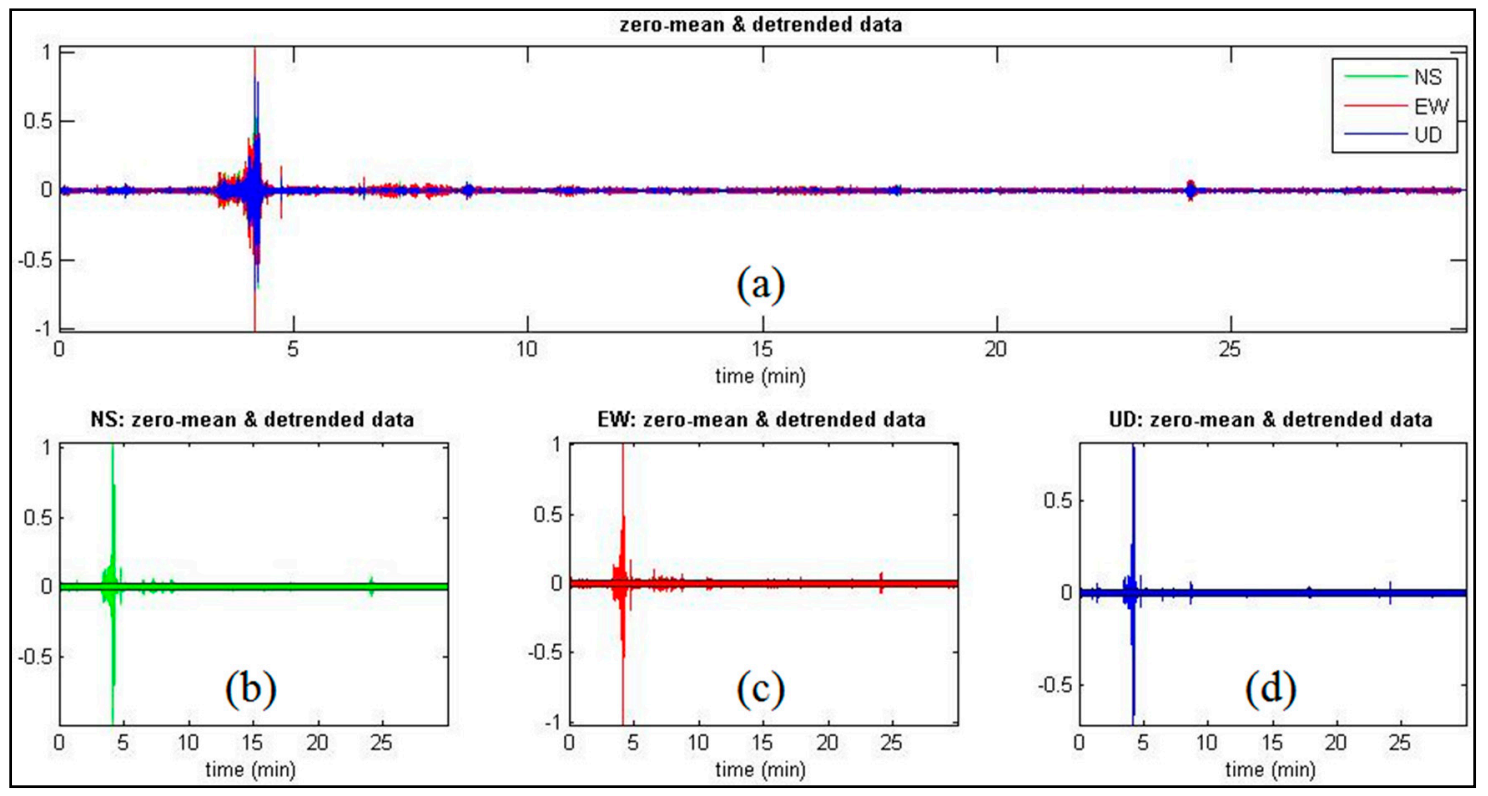

Figure 3. Examples of microtremor recording signals obtained in the field: (a) microtremor recording of the combined three components of NS, EW, and UD; (b) microtremor recording of the NS component; (c) microtremor recording of EW components; (d) microtremor recording of UD components.

After all field data were processed using Win-MASW 5.2 HVSR Software, amplification $\left(A_{g}\right)$ and predominant frequency $\left(f_{g}\right)$ values were obtained at each point of the study sites. The sample spectrum of the data processing results is shown in Figure 4. The vertical axis is the amplification component and the horizontal axis is the frequency component. 

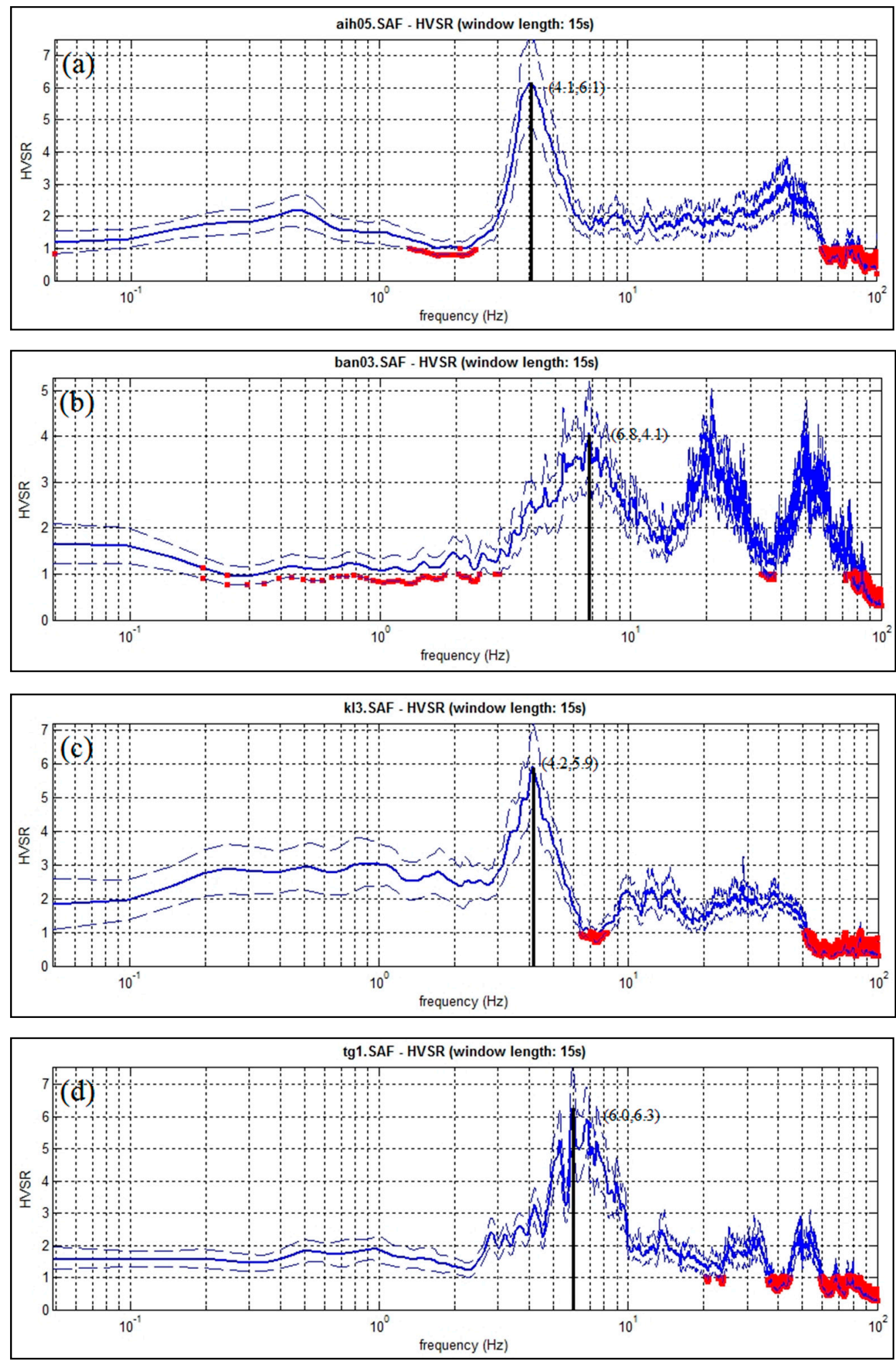

Figure 4. Example of the spectrum of data processing results to get the $f_{g}$ and $A_{g}$ value at data points with the predominant frequency and amplification respectively: (a) aih05 on (4.1 Hz and 6.1); (b) ban03 on (6.8 Hz and 4.1); (c) kl3 on (4.2 Hz and 5.9); (d) $\operatorname{tg} 1 \mathrm{on}(6.0 \mathrm{~Hz}$ and 6.3).

After obtaining the value of amplification and its predominant frequency, then reliability analysis can be performed. Reliability analysis is useful way to understand the validity of data. The data 
are classified to be reliable if they meet all the criteria proposed by SESAME. These criteria are: (i) $f_{g}>10 /$ window length; $I_{w}$ (ii) number of significant cycles, $n_{c}>200$; and (iii) standard deviation, $\sigma_{A}$ (current frequency, $f$ ) $<2$ for $0.5 f_{g}<f<2 f_{g}$ if $f_{g}>0.5 \mathrm{~Hz}$ or $\sigma_{A}(f)<3$ for $0.5 f_{g}<f<2 f_{g}$ if $f_{g}<0.5 \mathrm{~Hz}$. All data obtained in the field fulfill these criteria. In this study, a 15-s window is used in order to adequately cover the natural signal, allowing for more natural signals. The sampling rate of the measurement is from $5 \mathrm{~ms}(200 \mathrm{~Hz})$ to $10 \mathrm{~ms}(100 \mathrm{~Hz})$, so the upper limit of output frequency is from $100 \mathrm{~Hz}$ to $50 \mathrm{~Hz}$. However, taking into consideration the maximum output frequency limit as a whole, it is possible to have a very large output frequency value; the output frequency limit is $20 \mathrm{~Hz}$ because the expected frequency is merely the natural frequency.

\subsection{Predominant Frequency}

The predominant frequency varies from $0.7 \mathrm{~Hz}$ to $19.3 \mathrm{~Hz}$. The predominant frequency corresponds to the depth of bedrock. The lower the predominant frequency value, the greater the depth of the bedrock and vice versa. To obtain the predominant frequency distribution map in the study area, the kriging method is used. Kriging is a geostatistical method that exploits spatial values in the sampled locations and variograms to predict values in other uncharted and/or unsampled locations where the prediction value depends on its proximity to the sampled location [21]. A predominant frequency distribution map of the study area is shown in Figure 5.

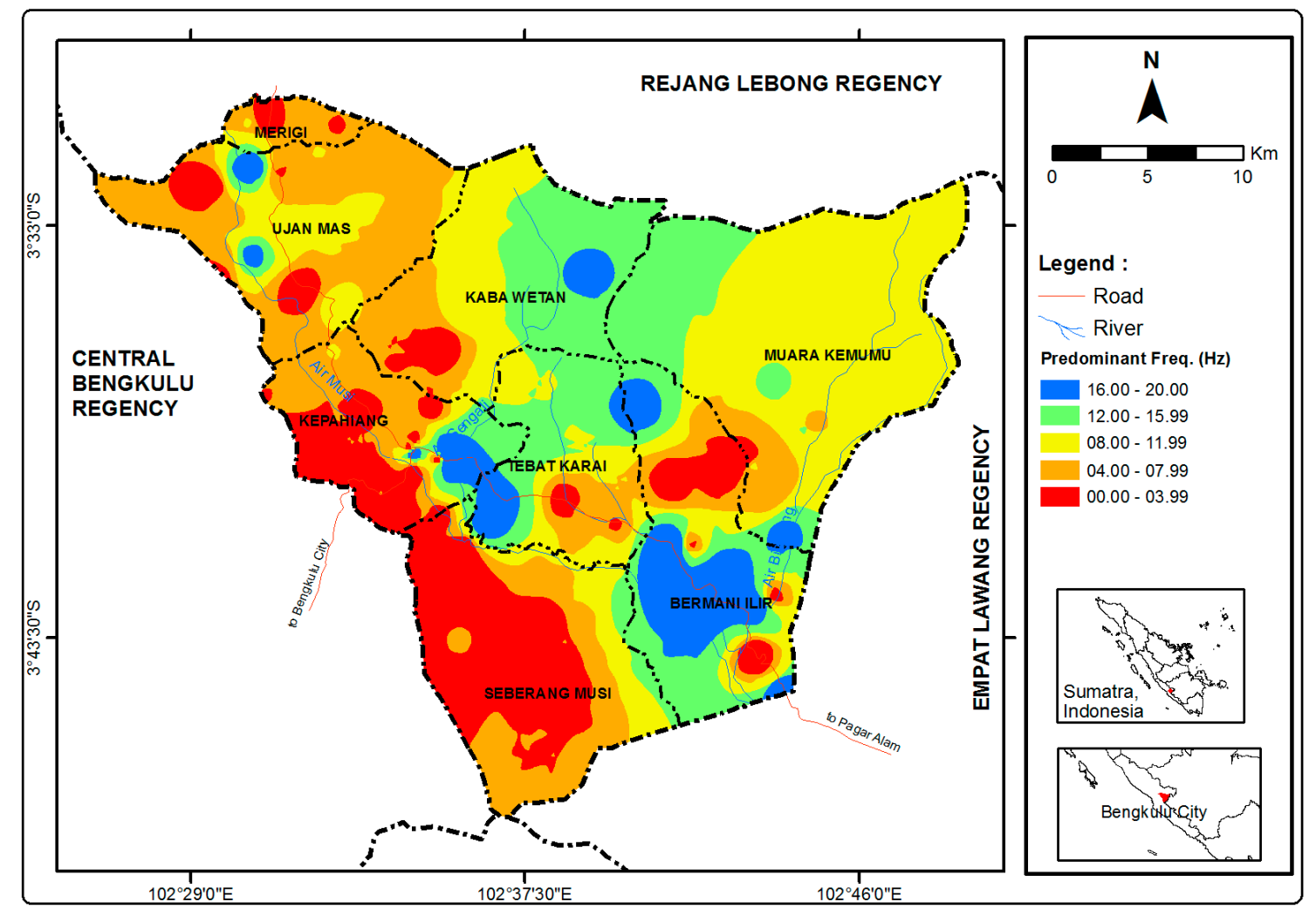

Figure 5. Map of the predominant frequency distribution in Kepahiang regency, Bengkulu province, Indonesia.

Figure 5 shows that the predominantly low frequency is located in the southwestern city of Kepahiang and extends to the southeast-northwest direction. The predominant frequency rises towards the slopes and has the highest value at the visible rock outcrop [22,23]. When a southwest-northeast incision is made, the predominant frequency will increase with the height of the topography of the slope, associated with the outcrop of the bedrock. This shows that the area has a shallow sedimentary layer. 
The amplification factor or HVSR spectrum ratio in the study sites varied from 1.5 to 13.5 . The ratio of HVSR spectra above hard rock shows response, with smaller peaks at higher frequencies. For the measurement point located above the thick sediment, it shows a sharper peak at a lower frequency. The HVSR ratio curve shows the contrast of impedance between the soft soil layers above the bedrock [23]. This study does not show a relationship between the predominant frequency and the resulting amplitude. Different amplification values may be found at the same frequency, as shown in Figure 6. According to Warnana [24], the distribution of high amplification factors across the measurement area indicates that the amplification factor is not determined only by topographic effects but also by some other factors, such as local geological factors. Indeed we need to be aware of areas with low predominant frequency values and high amplification values in seismic hazard analysis related to soft sediment thickness. The thick, soft sediment will affect the duration of the seismic waves that propagate at the site and will increase the amplitude of the wave, which can lead to damage to buildings.

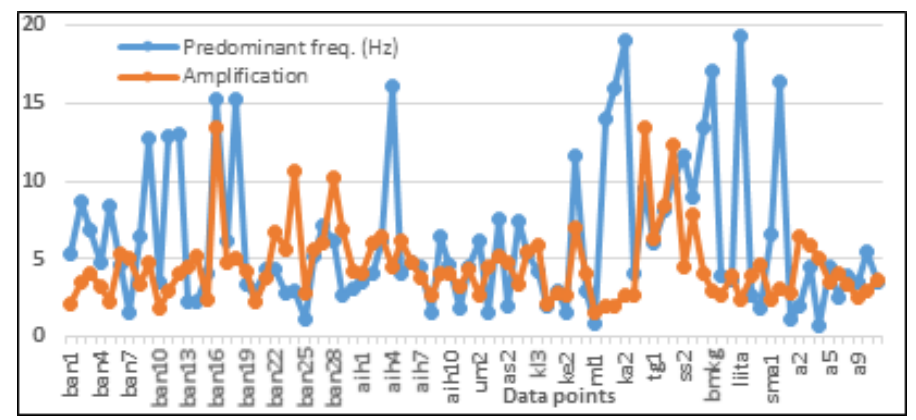

Figure 6. The predominant frequency value and its amplification at each measurement point. The labels of the $X$-axis in Figure 5 are names of the measuring stations.

\subsection{The Landslide Potential Map}

GSS values describe deformation conditions in the soil layer and they were determined based on the predominant frequency and amplification values obtained (the distribution of GSS values is shown in Figure 7). The GSS values can describe the deformation conditions occurring in the soil layer: according to Ishihara [25] they span from low $\left(10^{-6}-10^{-5}\right)$ to moderate $\left(10^{-4}-10^{-3}\right)$. At lower shear strain values, the soil layer only experience vibration, but in higher shear strain areas the soil can experience compaction, which can cause landslide or liquefaction. Application of ground characteristics associated with GSS levels was also proposed by Oliveira et al. [26], who showed the level of landslides occurrences during earthquakes in soil behavior. A large GSS value area has potential to run into landslides or liquefaction. GSS values of $10^{-2}-10^{-1}$ indicate the presence of landslide movement and ground collapse characteristics.

The GSS values obtained at the study sites vary from $1 \times 10^{-3}$ to $1.9 \times 10^{-2}$, which are moderate to high shear strain values. Based on the criteria from Ishihara [25] and Oliveira et al. [26], the ground may be elasto-plastic; even an earthquake around the Sumatran fault segment of Musi in Kepahiang can cause landslide and liquefaction phenomena in some places of weak zones with high GSS values.

In addition to the GSS value, to determine the landslide potential, this study performs weighting using SAW statistical methods involving other parameters such as rainfall, slope, distance of fault to measurement point, PGA, and Vs30. These parameters determine the weight value at each data point at the study area. Slope parameters are determined directly at the measurement areas, while the determination of rainfall, distance from faults to point of measurement, PGA, and Vs30 at each measurement point are based on research data that has been conducted by some previous researchers, like BMKG [27], Gafoer et al. [11], Irwanto et al. [12], Hadi and Brotopuspito [28], and Allen and Wald [29], as shown in Figures 8-11. 


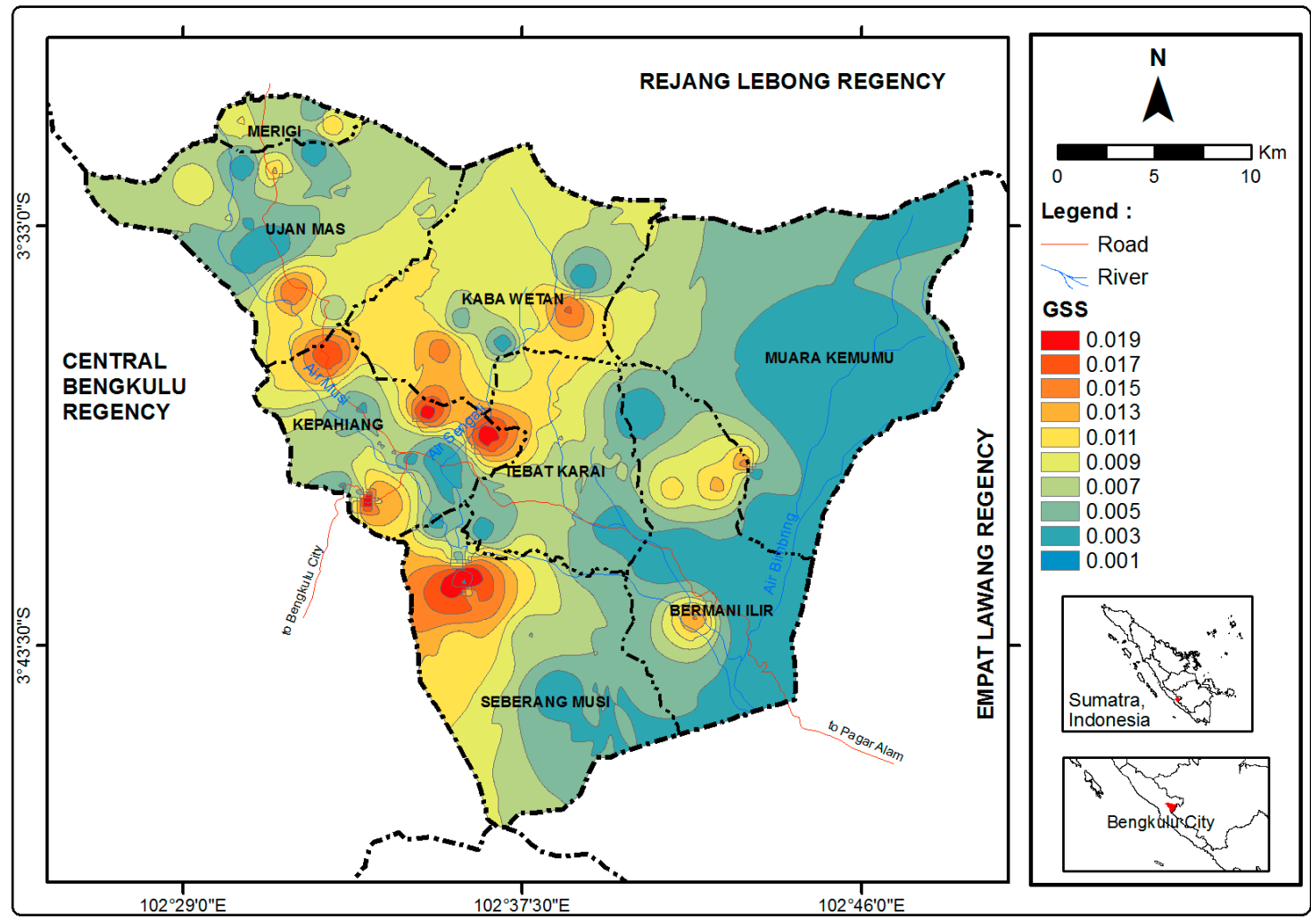

Figure 7. Distribution of GSS values in Kepahiang regency, Bengkulu province, Indonesia.

Figure 8 shows that the study area has very high average rainfall, from 2000 to $4000 \mathrm{~mm} /$ year. Areas with low rainfall are located in Bermani Ilir and Muara Kemumu subdistricts, while areas with high rainfall are located in Ujan Mas and Merigi subdistricts. However, most areas have an average rainfall of $>2500 \mathrm{~mm} /$ year [27]. The "Guidelines for Space Planning in Vulnerable Area to Landslides Disasters" in Indonesia [30], state that landslide-prone areas are areas with high precipitation from $70 \mathrm{~mm} / \mathrm{h}$ to $100 \mathrm{~mm} /$ day, with annual rainfall more than 2500/year [30]. High intensity of rainfall usually takes place within a short duration and covers a wide area.

Rain and earthquakes both provoke activation of landslide mechanisms. In particular, the magnitude of the earthquake relates to the extent of the landslide areas (for earthquake-induced landslides) and higher magnitudes increase the collapsed volumes [31,32]. This can be coupled with raining events lasting long enough for water to seep into a slope and favor soil mass collapse [33].

Figure 9 shows that the PGA value of bedrock in Kepahiang regency is quite high, $0.26 \mathrm{~g}$ up to $0.74 \mathrm{~g}$. PGA is the greatest acceleration of ground vibration ever occurring in a place caused by an earthquake and is called PGA bedrock if located on bedrock [34]. The value of PGA is obtained using the PSHA approach [22]. However, the resulting PGA map also involves all the faults around Kepahing regency, either main faults or secondary faults. Areas with high PGA values are unsafe zones where there is an earthquake threat. Indonesian National Board for Disaster Management (BNPB) [35] divides categories of threat into low, medium, and high PGA values. Therefore, the building or vital infrastructure must have a high resistance to high PGA and take into account the occurrence of earthquakes with large-scale magnitude [22]. Based on the relationship between PGA and modifiedercalli intensity (MMI) scale provided by Wald et al. [36] and the classification from Wood and Ratliff [37], the research area has a scale of MMI VII to MMI IX. The social impact of this situation can cause minor damage to houses of good construction, whereas poorly constructed buildings can undergo cracks and even destruction. At the same time, it may destroy strong buildings and cause the crook of home frames and foundation shifting of buildings. 


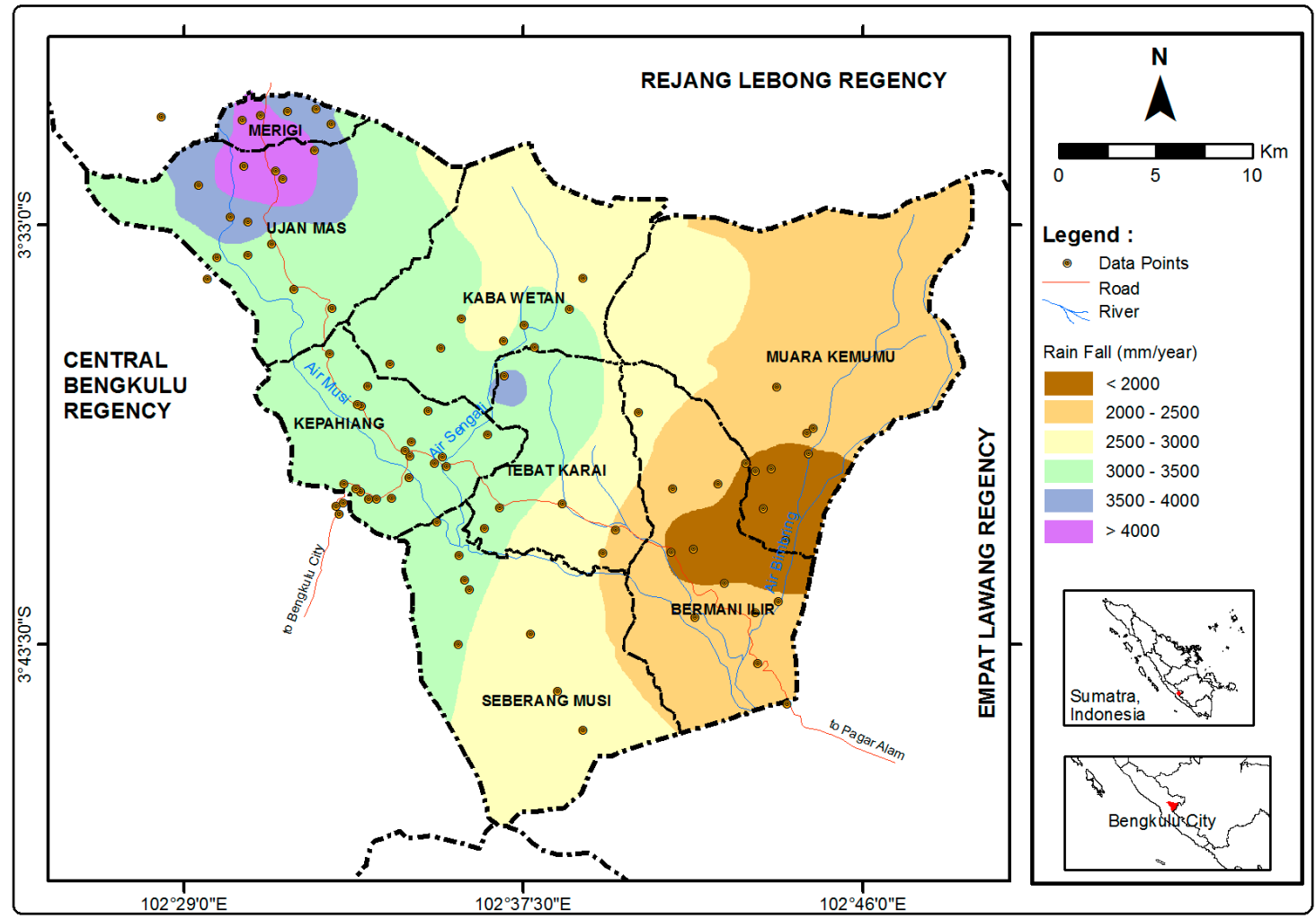

Figure 8. Map of the rainfall of Kepahiang regency, Bengkulu province, Indonesia (modified from BMKG [27]).

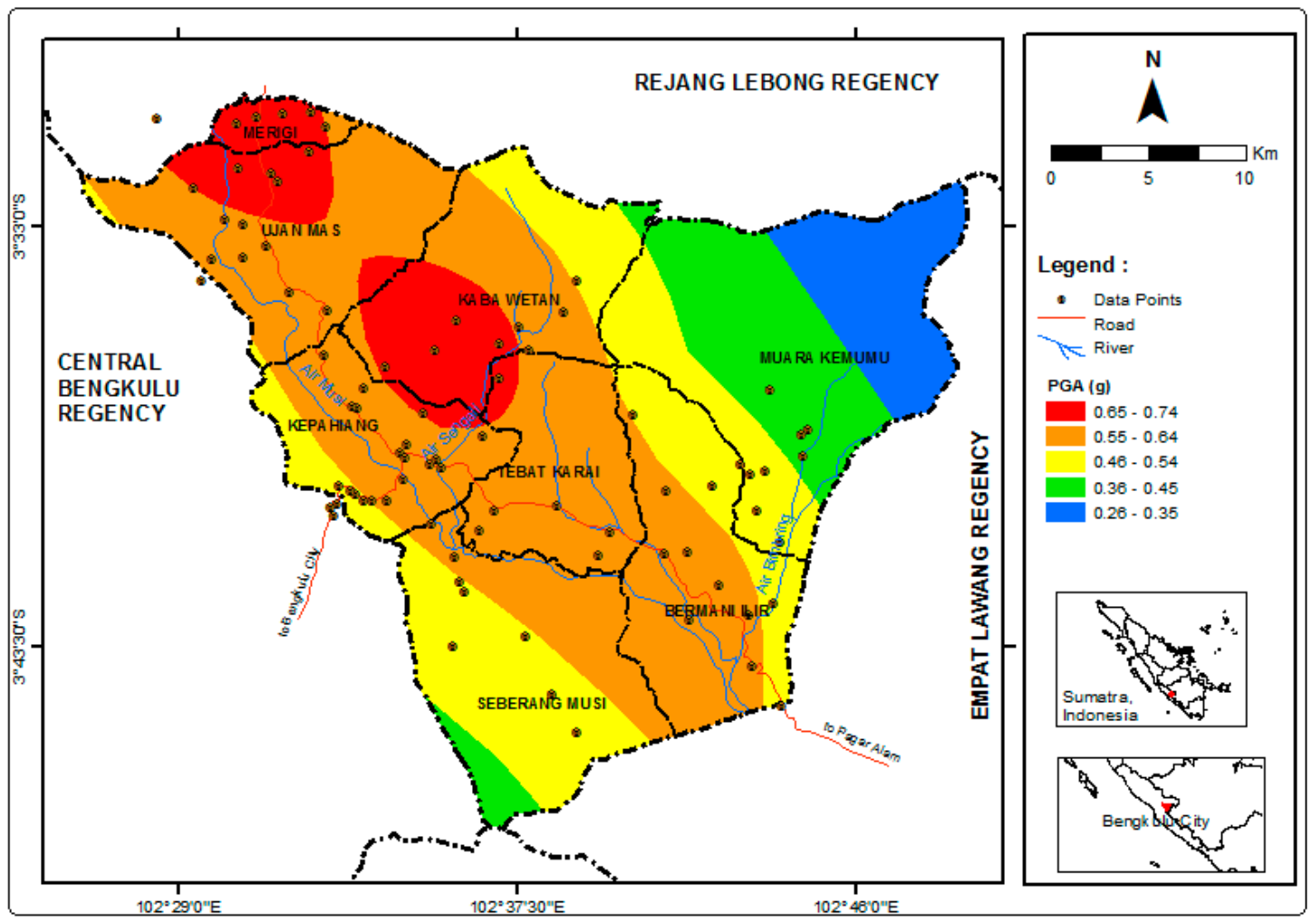

Figure 9. PGA bedrock map of Kepahiang regency, Bengkulu province, Indonesia (modified from Hadi and Brotopuspito [28]). 
The Vs30 map obtained comes from USGS data with a grid of observation points of about $1 \mathrm{~km}$. This map shows the magnitude of the medium soil shear strength against the shear movement. In terms of the geotechnical classification of the land, the value that impacts on the construction of the ground is up to a depth of $30 \mathrm{~m}$ (Vs30). Vs30 is the average velocity of shear wave up to a depth of $30 \mathrm{~m}$ from the ground surface. According to Wangsadinata [38], only layers of rock up to a depth of $30 \mathrm{~m}$ affect the magnification of earthquake waves. The Vs30 value indicates the magnitude of the shear modulus medium, particularly in the elastic properties of a medium [39], and is a very useful geotechnical parameter for seismic wave analysis. The values generated in the Vs30 distribution map are similar to topographic maps. This is because of the calculation to determine Vs30 using a topographic proxy [29]. Based on topographic proxies in general, flat-topped regions have lower Vs30 values than steep-topped ones.

Figure 10 shows that the distribution value of Vs30 in Kepahiang regency varies from 211 to $681 \mathrm{~m} / \mathrm{s}$. Areas with low Vs30 values are at more risk of earthquakes. This is due to the seismic wave velocity through the rocks depending on its stiffness. The softer the rock, the lower the seismic wave velocity in the rock will be and vice versa. Earthquake shocks in areas with low Vs30 values are at risk of severe damage. If it happens in the slope area, there is a risk of a landslide. The division of the index class for the Vs30 category refers to SNI 1726-2012 [40], where a low Vs30 value means a higher risk of earthquake or landslide.

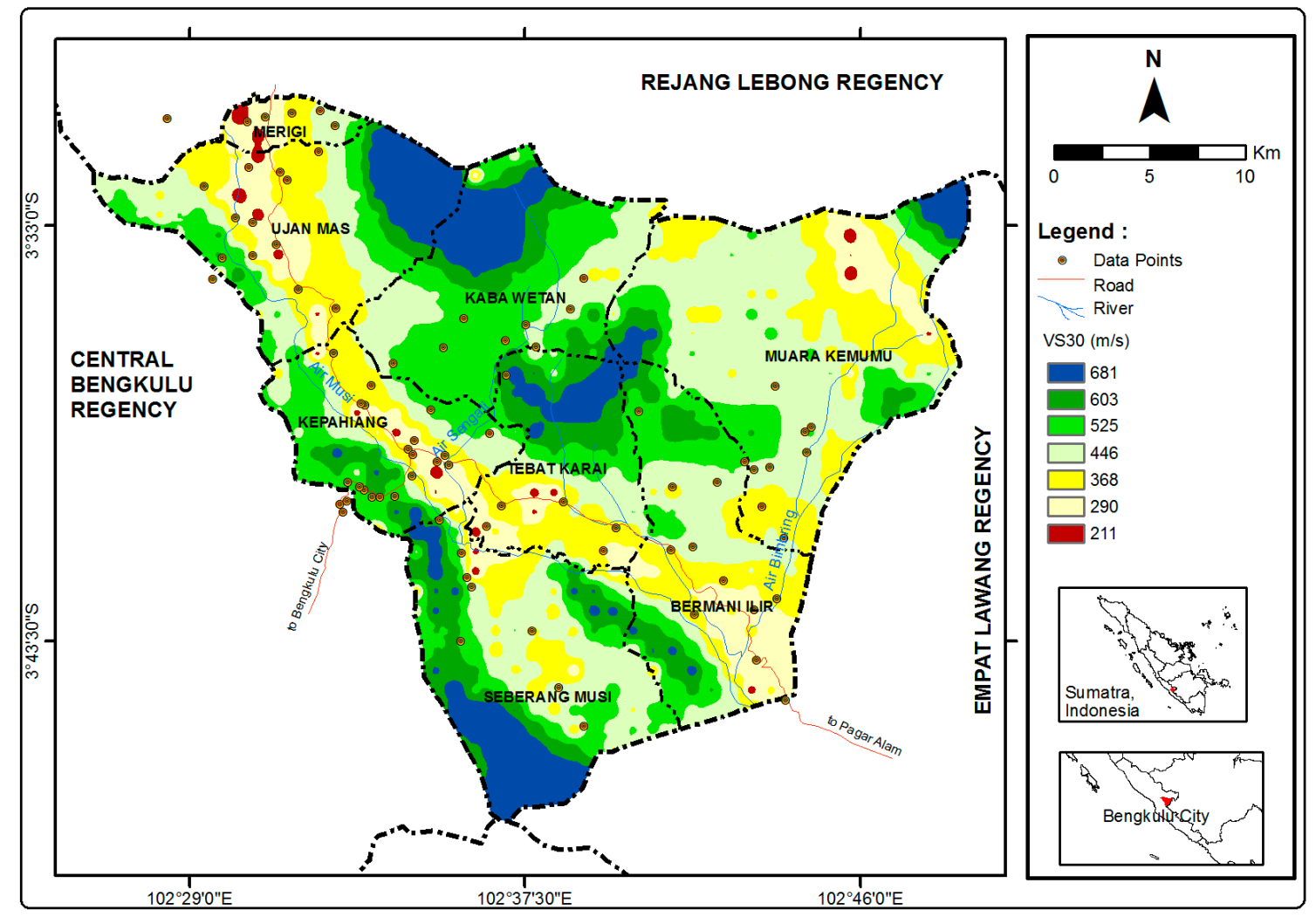

Figure 10. Vs30 map of Kepahiang regency, Bengkulu province, Indonesia (modified from Allen and Wald [29]).

Landslide potential is also heavily influenced by the slope. Zuidam [41] classifies the slope index class into seven classes, from flat to steep. The slope index class also depends on the field conditions in the study area. The field conditions in the form of areas that have experienced landslides with a certain slope angle are included in a high potential classification that generally has a steepness greater than $40^{\circ}$. Steep slopes have a great risk of landslides. In the study, steepness of slope is divided into three classes of indexes, namely flat-moderately steep, very steep, and extremely steep. 
The landslide potential classification is determined from the weighted value of SAW. The range of values obtained is then divided into three classes, with the highest value range for high landslide potential class, medium value range for medium landslide potential, and the lowest value range for low landslide potential. Indicators of weighting criteria and performance ratings on each of the parameters are shown in Table 1. The appropriate weighting criteria and index classes refer to "Regulation of the Head of the National Agency for Disaster Management Number 02 Year 2012 on General Guidelines for Disaster Risk Assessment" in Indonesia [35]. To the most influential indicator is given the highest weight. This is based on the performance rating criteria shown in Table 1 , in which each indicator obtained a preference value for each selected alternative. The final result is the landslide potential map of Figure 11.

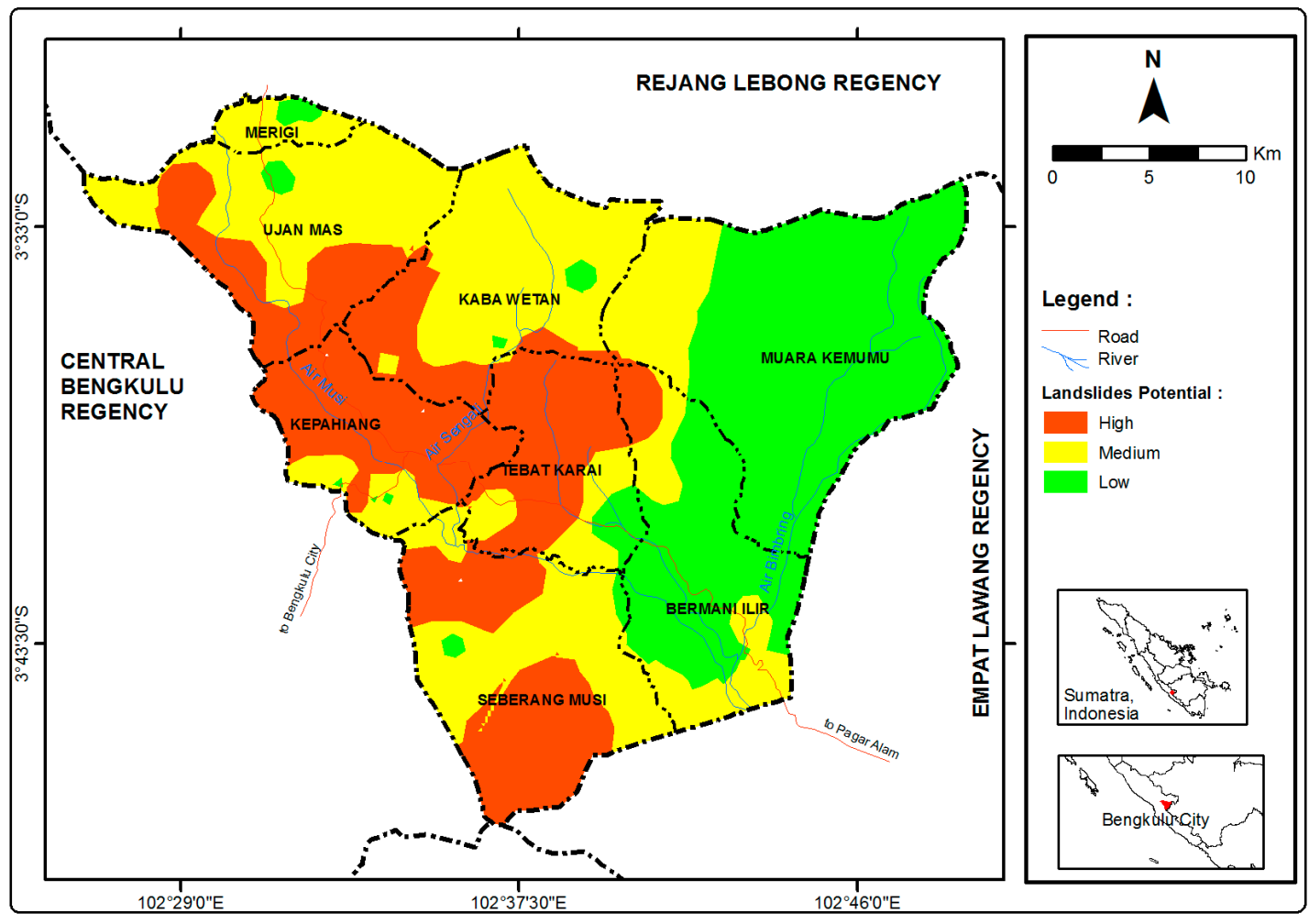

Figure 11. Landslide potential map of Kepahiang regency, Bengkulu province, Indonesia.

Table 1. Indicator, criterion weight, and performance rating of each parameter in the earthquakeprone area.

\begin{tabular}{|c|c|c|c|c|}
\hline Indicator & Criterion Weight & Level of Susceptibility & Index Class & Performance Rating \\
\hline \multirow{3}{*}{$\begin{array}{l}\text { Ground shear } \\
\text { strain (GSS) }\end{array}$} & \multirow{3}{*}{5} & High & GSS $\geq 0.01$ & 3 \\
\hline & & Medium & $0.0001 \leq \mathrm{GSS} \leq 0.01$ & 2 \\
\hline & & Low & GSS $\leq 0.0001$ & 1 \\
\hline \multirow{3}{*}{ Rainfall (mm/year) } & \multirow{3}{*}{3} & High & Rainfall $\geq 2500 \mathrm{~mm} /$ year & 3 \\
\hline & & Medium & $1000 \mathrm{~mm} /$ year $\leq$ rainfall $\leq 2500 \mathrm{~mm} /$ year & 2 \\
\hline & & Low & Rainfall $\leq 1000 \mathrm{~mm} /$ year & 1 \\
\hline PGA (g) & 2 & Low & PGA $<0.26 \mathrm{~g}$ & 1 \\
\hline \multirow{3}{*}{$\operatorname{Vs} 30(\mathrm{~m} / \mathrm{s})$} & \multirow{3}{*}{4} & High & $\mathrm{Vs} 30 \leq 350 \mathrm{~m} / \mathrm{s}$ & 3 \\
\hline & & Medium & $350 \mathrm{~m} / \mathrm{s} \leq \mathrm{Vs} 30 \leq 750 \mathrm{~m} / \mathrm{s}$ & 2 \\
\hline & & Low & $\mathrm{Vs} 30 \geq 750 \mathrm{~m} / \mathrm{s}$ & 1 \\
\hline Slope $\left(^{\circ}\right)$ & 3 & High & Slope $>40^{\circ}$ & 3 \\
\hline $\begin{array}{l}\text { Distance from the } \\
\text { fault }(\mathrm{km})\end{array}$ & 3 & Low & Distance from the fault $\geq 5 \overline{\mathrm{km}}$ & 1 \\
\hline
\end{tabular}


In Figure 11, landslide potential is divided into three categories, namely low, medium, and high. The areas with high potential need to be more aware of the threat of landslides, especially in population-dense areas such as settlements where there is building and road infrastructure. In the event of a landslide in these areas, there can be casualties as well as damage to transportation networks. These areas are located in the Ujan Mas, Kepahiang, Kabawetan, Tebat Karai, Bermani Ilir, and Seberang Musi subdistricts.

\section{Discussion and Conclusions}

The area traversed by the Sumatran fault in Kepahiang is a fertile area because it is covered by young volcanic materials [42,43]. A consequence of this situation is an increase in settlements and related infrastructures. These physical infrastructures come at a risk of loss during earthquakes which can also trigger landslides collapses. Indeed the vibrations caused by earthquakes can trigger landslides by weakening the bonding force between grains of soil or particles of rock on slopes [33]. In addition according to Khanh [44], this process is enhanced by the rapid infiltration of water due to widening of cavities within soil material caused by earthquake vibrations.

The results of our study show that Kepahiang regency, Bengkulu province, Indonesia has areas of high landslide potential due to the Sumatran fault movement of the Musi active segment. In particular there is a risk of slopes collapse and of landslides potentially covering populated areas, highways, infrastructure facilities, thereby causing mass casualties. Indeed, according to earthquake records from the United States Geological Service [45], on 15 December 1979 there was a devastating earthquake $(\mathrm{Ms}=6.6)$ with a depth of $33 \mathrm{~km}$ around the Sumatran fault segment of Musi, causing fissures and major landslides and nearly 500 houses were destroyed [42]. The most damaged areas are in Daspetah, Ujan Mas subdistrict. In particular, we have classified landslide potential in Kepahiang regency into three categories, namely low, medium and high potential. Areas that have high potential, such as Ujan Mas, Kepahiang, Kabawetan, Tebat Karai, Bermani Ilir, and Seberang Musi subdistricts are at greater risk from landslide disasters, especially in densely populated areas. Hence it is important that buildings and infrastructure are built in this area to resist earthquake shocks and that they are not constructed in areas of high landslide potential.

Author Contributions: A.I.H. prepared the initial draft article and its analysis. K.S.B. designed the acquisition of field data and examined the results. S.P. contributed to the analysis of landslide potential map results. H.C.H. corrected the weighting and analyzed the results. All authors contributed to the writing of the manuscript, correcting the results, and final editing of the manuscript.

Acknowledgments: We thank ICS, USGS, and BMKG for the earthquake catalogue data and the Geophysics Laboratory of Physics Department, Faculty of Mathematics and Natural Sciences, University of Bengkulu, Indonesia for the use of tools for field data acquisition, and KEMRISTEKDIKTI for providing a Ph.D. scholarship at UGM, Yogyakarta, Indonesia.

Conflicts of Interest: The authors declare no conflict of interest.

\section{References}

1. Sudrajat, A. Bengkulu as a Disaster Risk Areas; Indonesian Agency for Meteorology, Climatology and Geophysics: Jakarta, Indonesia, 2007; pp. 1-5.

2. Gafoer, S.; Amin, T.C.; Pardede, R. Geology of the Bengkulu Quadrangle, Sumatra; Department of Mines and Energy, Directorate General of Geology and Mineral Resources, Geological Research and Development Centre: Bandung, Indonesia, 2012; pp. 9-35.

3. Sieh, K.; Natawidjaja, D.H. Neotectonics of the Sumatran fault, Indonesia. J. Geophys. Res. 2000, 105, 28295-28326. [CrossRef]

4. Zhang, S.; Zhang, L.M.; Glade, T. Characteristics of earthquake and rain-induced landslides near the epicenter of Wenchuan earthquake. Eng. Geol. 2014, 175, 58-73. [CrossRef]

5. Karnawati, D. Mechanism of mass movement of rocks due to earthquake: Overview and analysis of technical geology. J. Dinamika Teknik Sipil 2007, 7, 179-190. 
6. Hasi, B.; Ishii, Y.; Maruyama, K.; Nakamura, A.; Hara, Y. Controls on Distribution and Scale of Earthquake Induced Landslides Caused by the Iwate-Miyagi Inland Earthquake in 2008, Japan; Geophysical Research Abstracts, EGU2010-3827-4; European Geosciences Union (EGU) General Assembly: Vienna, Austria, 2010; Volume 12.

7. Djadja; Sutikno; Suparman, T.; Iskak, M.; Ronald, F.; Reawaru, O. Report on Mapping of Land Movement Vulnerability Zone in Kepahiang and Surrounding Area, Bengkulu; Center for Volcanology and Geological Hazard Mitigation, Geological Agency, Department of Mineral Resources: Bandung, Indonesia, 2009; pp. 1-60.

8. Sukisno; Muin, S.N. Prediction of Landslide Prone Areas in Kepahiang Regency by Using Geographic Information System; Seminar Nasional Menuju Pertanian Yang Berdaulat; Faculty of Agriculture, University of Bengkulu: Bengkulu, Indonesia, 2012; pp. 621-629.

9. Hadi, A.I.; Sismanto; Brotopuspito, K.S. Landslide potential analysis using microtremor and slope data on Bengkulu-Kepahiang Main Road at Km 31-60. IOSR J. Appl. Geol. Geophys. 2016, 4, 9-14. [CrossRef]

10. Taufik, R.; Rahmat, B.S. Landslide analysis in deep claystone deposits and handling, Cipularang toll road, a case study at KM $92+650$ and KM $92+800$. J. Widyariset. 2006, 9, 79-92.

11. Gafoer, S.; Amin, T.C.; Pardede. Geological Map of Bengkulu Quadrangle, Sumatra; Department of Mines and Energy, Directorate General of Geology and Mineral Resources, Geological Research and Development Centre: Bandung, Indonesia, 2007.

12. Irwanto, H.; Jaya, D.; Miansyah, A.; Septiawan, A.; Girsang, R.; Margiana. Final Report of Mineral and Rock Inventory of Fiscal Year 2013; Mining Office of Energy and Mineral Resources, Kepahiang Regency: Kepahiang, Indonesia, 2013.

13. SESAME. Guidelines for the Implementation of the H/V Spectral Ratio Technique on Ambient Vibrations: Measurements, Processing and Interpretation; Project No. EVG1-CT-2000-00026 SESAME; European Commission-Research General Directorate: Brussels, Belgium, 2004; pp. 8-31.

14. Bullen, K.E. An Introduction to the Theory of Seismology, 3rd ed.; Cambridge University Press: Cambridge, UK, 1987; pp. 231-234, ISBN 0-521-04367-0.

15. Kramer, S.L. Geotechnical Earthquake Engineering; Prentice-Hall: Upper Saddle River, NJ, USA, 1996; pp. 45-124, ISBN 0-13-374943-6.

16. Nakamura, Y.; Saita, J.; Sato, T. Development of vulnerability assessment models using microtremor/strong motion. In Proceedings of the 6th EQTAP Workshop, Kashikojima, Japan, 1-2 December 2003.

17. Nakamura, Y. On the H/V spectrum. In Proceedings of the 14th World Conference on Earthquake Engineering, Beijing, China, 12-17 October 2008.

18. Fell, R.; Corominas, J.; Bonnard, C.; Cascini, L.; Leroi, E.; Savage, W.Z. Guidelines for landslide susceptibility, hazard and risk zoning for land-use planning on behalf of the JTC-1 Joint Technical Committee on Landslides and Engineered Slopes. Eng. Geol. 2008, 102, 99-111. [CrossRef]

19. Soeters, R.; Westen, C.J.V. Slope instability recognition, analysis and zonation. In Landslides: Investigation and Mitigation; Turner, A.K., Schuster, R.L., Eds.; Transportation Research Board, National Research Council, National Academy Press: Washington, DC, USA, 1996; pp. 129-177.

20. Kusumadewi, S.; Hartati, S.; Harjoko, A.; Wardoyo, R. Fuzzy Multi-Attribute Decision Making (Fuzzy MADM), 1st ed.; Graha Ilmu: Yogyakarta, Indonesia, 2006; pp. 69-81, ISBN 10-979-756-125-.

21. Matheron, G. Principles of geostatistics. Econ. Geol. 1963, 58, 1246-1266. [CrossRef]

22. Daryono. Seismic Vulnerability Index Based on Microtremor at Each Unit Landforms in Bantul Graben Zone, Yogyakarta Special Region. Ph.D. Thesis, Universitas Gadjah Mada, Yogyakarta, Indonesia, 2011.

23. Eskisar, T.; Ozyalin, S.; Kuruoglu, M.; Yilmaz, H.R. Microtremor measurements in the northern coast of Izmir Bay, Turkey to evaluate site-specific characteristics and fundamental periods by $H / V$ spectral ratio method. J. Earth Syst. Sci. 2013, 122, 123-136. [CrossRef]

24. Warnana, D.D.; Soemitro, R.A.A.; Utama, W. Application of microtremor HVSR method for assessing site effect in residual soil slope. IJBAS IJENS 2011, 11, 100-105.

25. Ishihara, K. Soil Behaviour in Earthquake Geotechnics; Oxford University Press Inc.: New York, NY, USA, 1996.

26. Oliveira, C.S.; Roca, A.; Goula, X. Assessing and Managing Earthquake Risk; Geo-Scientific and Engineering Knowledge for Earthquake Risk Mitigation: Developments, Tools, Techniques; Springer: Dordrecht, The Netherlands, 2008; pp. 67-78, ISBN 13-978-1-4020-3608-8.

27. BMKG. Annual Report on Rainfall in Bengkulu Province; Indonesian Agency for Meteorology, Climatology and Geophysics: Bengkulu, Indonesia, 2016. 
28. Hadi, A.I.; Brotopuspito, K.S. Mapping of peak ground acceleration using probabilistic seismic hazard analysis (PSHA) approach in Kepahiang regency of Bengkulu province. J. Berkala Fisika 2015, 18, 101-112.

29. Allen, T.I.; Wald, D.J. Topographic Slope as a Proxy for Global Seismic Site Conditions (Vs30) and Amplification around the Globe; Open-File Report 2007-1357; U.S. Geological Survey: Reston, GA, USA, 2007; 69p.

30. Kirmanto, D. Guidelines for Space Planning in Vulnerable Area to Landslides Disaster; Directorate General of Space Planning, Department of Public Works: Jakarta, Indonesia, 2007.

31. Keefer, D.K. Landslides caused by earthquakes. Bull. Geol. Soc. Am. 1984, 95, 406-421. [CrossRef]

32. Nepop, R.K.; Agatova, A.R. Estimating magnitudes of prehistoric earthquakes from landslide data: First experience in southern Altai. Russ. Geol. Geophys. 2008, 49, 144-151. [CrossRef]

33. Karnawati, D. Natural Disasters, Land Mass Movement in Indonesia and Handling It; Jurusan Teknik Geologi, Fakultas Teknik, Universitas Gadjah Mada: Yogyakarta, Indonesia, 2005; pp. 16-23, ISBN 979-95811-3-3.

34. Brotopuspito, K.S.; Prasetya, T.; Widigdo, F.M. Peak ground acceleration of Yogyakarta special region 1945-2006. J. Geofisika 2006, 1, 19-22.

35. Indonesian National Board for Disaster Management (BNPB). Regulation of the Head of National Agency for Disaster Management Number 02 Year 2012 on General Guidelines for Disaster Risk Assessment; BNPB: Jakarta, Indonesia, 2007.

36. Wald, D.J.; Quitoriano, V.; Heaton, T.H.; Kanamori, H. Relationships between peak ground acceleration, peak ground velocity, and modified Mercalli intensity in California. J. Earthq. Spectra 1999, 15, 557-564. [CrossRef]

37. Wood, N.; Ratliff, J. Population and Business Exposure to Twenty Scenario Earthquakes in the State of Washington; Open-File Report 2011-1016; U.S. Geological Survey: Reston, GA, USA, 2011; 13p.

38. Wangsadinata, W. Earthquake Resistant Building Planning Based on SNI 1726-2002, Shortcourse HAKI 2006; Wiratman \& Associates Chairman SNI-1726-2002 Committee: Jakarta, Indonesia, 2006.

39. Hartantyo, E. The Mapping of Shear Wave Velocity Profiles and Their Implications to Liquefaction in the Volcaniclastic Sediments, South Flank of Merapi Volcano, Yogyakarta. Ph.D. Thesis, Universitas Gadjah Mada, Yogyakarta, Indonesia, 2015.

40. SNI 1726-2012. Earthquake Resistance Planning Procedure for Building Structure and Non Building; National Standardization Agency of Indonesia: Jakarta, Indonesia, 2012.

41. Zuidam, R.A.V. Guide to Geomorphological Aerial Photographic Interpretation and Mapping; ITC Eschede: Eschede, The Netherlands, 1983 ; pp. 38-45.

42. Sukmono, S. Fractal Analysis of Seismicity Mechanics for Sumatran Fault System. Ph.D. Thesis, Institut Teknologi Bandung, Bandung, Indonesia, 1997.

43. Arsadipura, S.; Kholid, M.; Djuhardi, D. Integrated Geophysical Investigation on Gravity, Geomagnet and Geo-Electrical at Kepahiang Geothermal Area of Kabawetan Sub-District, Kepahiang Regency, Bengkulu Province; Geological Resource Center Activities Results: Jakarta, Indonesia, 2010; pp. 653-664.

44. Khanh, N.Q. Landslide Hazard Assessment in Muonglay, Vietnam Applying GIS and Remote Sensing. Ph.D. Thesis, Faculty of Mathematics and Natural Sciences, Ernst-Moritz-Arndt-University Greifswald, Greifswald, Germany, 2009.

45. USGS. Search Earthquake Archives. Available online: http://earthquake.usgs.gov/earthquakes/search/ (accessed on 9 July 2015).

(C) 2018 by the authors. Licensee MDPI, Basel, Switzerland. This article is an open access article distributed under the terms and conditions of the Creative Commons Attribution (CC BY) license (http://creativecommons.org/licenses/by/4.0/). 